DOI: http://dx.doi.org/10.15688/jvolsu10.2014.6.5

УДК 551.46

ББК 26.221

\title{
A NEW CONCEPT OF PHOTOSYNTHESIS
}

\author{
Komissarov Gennadiy Germanovich
}

Doctor of Chemical Sciences, Professor,

N. N. Semenov Institute for Chemical Physics, RAS

komiss@chph.ras.ru,gkomiss@yandex.ru

Kosygina St., 4, 119991 Moscow, Russian Federation

\begin{abstract}
The history of the formation of a new concept of photosynthesis proposed by the author is considered for the period since 1966 to 2013. Its essence consists in the following facts: the photosynthetic oxygen (hydrogen) source is not water, but exo- and endogenous hydrogen peroxide; thermal energy is a necessary part of the photosynthetic process; along with the carbon dioxide the air (oxygen, inert gases) is included in the photosynthetic equation. The mechanism of the photovoltaic (Becquerel) effect in films of chlorophyll and its synthetic analogue - phthalocyanine are briefly touched upon in the article. The article presents the works on artificial photosynthesis performed in the laboratory of Photobionics of N.N. Semenov Institute of Chemical Physics, RAS.

Key words: photosynthesis, artificial photosynthesis, photovoltaic effect, photocells, quantum yield to a photocurrent, chloroplast, transpirations.
\end{abstract}

Photosynthesis is the GLOBAL, FUNDAMENTAL and UNIQUE biological process. The mechanism of its study is one of the central tasks of the modern natural science. Investigations on photosynthesis started in 1771, when the outstanding English chemist Joseph Priestley discovered the capacity of plants to 'repair air, distorted by the burning of candles', i.e. release oxygen. A significant contribution to the development of the concept was introduced by Ingen-Housz, who showed the necessity of solar light for the occurrence of photosynthesis: the release of oxygen occurs only if the plants are illuminated (in darkness, they lose this capacity). He also established that photosynthesis $\dot{*}$ is accompanied by the buildup of organic products. The experiments carried out by J. Senebier and N.Th. Saussure revealed initial substances of photosynthesis (carbon dioxide and water). The energy aspect of the problem was discussed for the first time by J.R. Mayer. In
1941, A.P. Vinogradov and R.V. Teis in USSR and S. Ruben with his colleagues in the USA established that oxygen is released from the water and not from the carbon dioxide [27]. During the last 70 years the main equation of photosynthesis does not change, and the following is written:

$$
\mathrm{CO}_{2}+\mathrm{H}_{2} \mathrm{O} \stackrel{\text { Light }}{\longrightarrow} \text { carbohydrates }+\mathrm{O}_{2} . \text { (1) }
$$

During breathing (reaction (1) taking place from the left to the right), the energy stored in the final products by the plants is released. It should also be mentioned that all living substances are constructed from molecules which are initially formed in plants. Examination of the unique biological process of storage of solar energy has been continuing for more than two centuries, but the final mechanism has not as yet been completely explained. 


\section{Functional modeling of photosynthesis}

Regardless of the complexity of photosynthesis, it is possible to define two main stages in this process: the light stage, whose occurrence requires the direct effect of light, and the dark stage, which follows the light stage. It is assumed that the first, light stage, is characterized by the occurrence of photosplitting of water with the generation of molecular oxygen which is injected into the atmosphere as a secondary product:

$$
\mathrm{H}_{2} \mathrm{O} \stackrel{\text { Light }}{\longrightarrow}[\mathrm{H}]+\mathrm{O}_{2} \text {. }
$$

The resultant hydrogen subsequently enters to the thermal cycle of the fixation of carbon dioxide which is completed with the formation of carbohydrates, conventionally denoted by $\left\{\mathrm{CH}_{2} \mathrm{O}\right\}$ :

$$
[\mathrm{H}]+\mathrm{CO}_{2} \stackrel{\text { Ferments }}{\longrightarrow}\left\{\mathrm{CH}_{2} \mathrm{O}\right\} .
$$

This stage, including a large number of fermentation reactions, has been examined in detail in studies by the outstanding American chemists M. Calvin who was awarded the Nobel prize in 1961.

Thus, the PHOTOSYNTHESIS consists of two main stages: the PHOTOlysis of water and dark SYNTHESIS of carbohydrates. In the second stage, there are no specific PHOTOsynthesic process, the fixation of carbon dioxide in the darkness may be carried out by the liver cells of a rat, if a suitable donor of hydrogen is available.

In this article, we shall approach the problem of photosynthesis from the physical-chemical position. Can artificial physical-chemical systems reproduce the light stage of photosynthesis?

The sequence of transformation of energy during photosynthesis, as described in $[23 ; 27 ; 32]$, may be written in the following form:

$$
\mathrm{E}_{\mathrm{L}} \rightarrow \mathrm{E}_{\mathrm{E}} \rightarrow \mathrm{E}_{\mathrm{C}},
$$

where $E$ is the energy with the appropriate indexes 'light', 'electrical', 'chemical'.

The equation (4) greatly simplified the problem of functional modelling of photosynthesis because it made it possible to solve the problem in two independent stages:

$$
\begin{aligned}
& \mathrm{E}_{\mathrm{L}} \rightarrow \mathrm{E}_{\mathrm{E}}, \\
& \mathrm{E}_{\mathrm{E}} \rightarrow \mathrm{E}_{\mathrm{C}}
\end{aligned}
$$

and transformation (6) (electrolysis of water with the release of gaseous oxygen) has been solved a long time ago. On the industrial scale, the process is carried out with high efficiency (current efficiency is $95-99 \%$ ). Thus, the initial task is to find a device capable of generating electrical energy under the effect of light.

In 1839, E. Becquerel [3] described the first of sometimes detected photoeffects. The principle of the phenomenon, subsequently referred to as the Becquerel effect, or photovoltaic effect, is the formation of a difference of the potentials between two metallic electrodes placed in an electrolyte; one of the electrodes is coated with a layer of a light-sensitive substance.

In 1874, Becquerel observed that the illumination of a silver-coated platinum electrode, carrying a chlorophyll film, with red light, changes its potential [4]. We believe that this date should be regarded as the basic date in the physicalchemical modeling of photosynthesis, although Becquerel never mentioned this approach. His work was directed to confirm the phenomenon of optical sensitisation in photography, discovered by H.W. Vogel [6].

Prior to starting modelling experiments, we regarded it as essential to evaluate (at least approximately) the intensity of the photoflux in chloroplast. Using the Faraday law, it can easily be shown that the total current in chloroplasts, containing $0.1 \mathrm{mg}$ of chlorophyll, is equal to $10^{-5} \mathrm{~A}$. However, in a single chloroplast, the current is obviously many times smaller $\left(10^{-13} \mathrm{~A}\right)$.

In 1966, as a functional model of chloroplast, we proposed a photovoltaic battery $[23 ; 27 ; 32]$. Its first in the world variant was realized at the Institute of Chemical Physics of the Academy of Sciences of the USSR in 1968 [22; 23; 33]. Then a similar battery was built in the USA [50]. The battery consisted of 4 electrodes coated with a synthetic analogue of chlorophyll, i.e. phthalocyanine. The battery was characterized by the following parameters [33]: the light potential reached $2.4 \mathrm{~V}$, which is fully sufficient for electrolysis of water with the generation of molecular oxygen (the dissociation potential of water $1.23 \mathrm{~V}$ ); the current, taken from the battery 


\section{ТЕХНИКО-ТЕХНОЛОГИЧЕСКИЕ ИННОВАЦИИ}

was $5.6 \times 10^{-5}$ A so that it was possible to record oxygen by the conventional methods. The quantum yield of the photocurrent was not high, 0.01-0.1\%.

The proposed device is capable of releasing oxygen from water under the effect of visible light, i.e. reproduce one of the main functions of the chloroplast, and the process, taking place in the battery, is of the photocatalytic nature.

\section{The Bequrel effect in phtalocianine films}

The maximum value of the quantum yield of the photocurrent is detected in the case of monomolecular coating of the electrode with the pigment [13] (Fig. 1). In the chloroplast, the membranes are also covered on average by a monomolecular layer of chlorophyll.

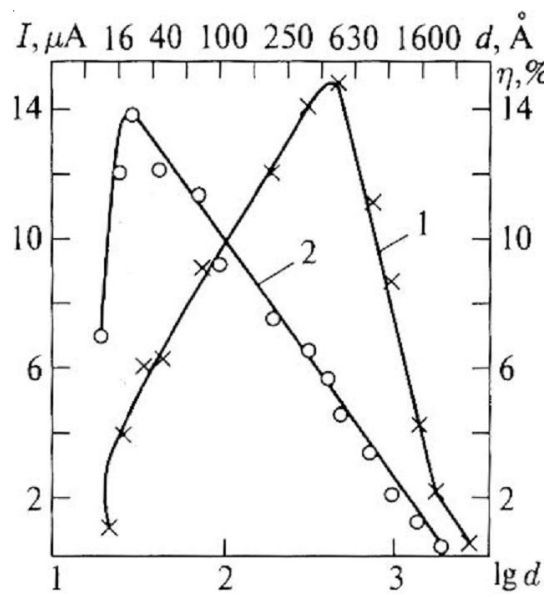

Fig. 1. Dependence of the short circuit current (curve 1) and the quantum yield (curve 2) on the thickness of the pigment film

To increase the quantum yield, it was necessary to carry out a systematic examination of the mechanism of the Becquerel effect. This was carried out in our laboratory. As a result, the quantum yield was increased to units and, subsequently, to tens of percent $[13 ; 14 ; 27 ; 34$; $35]$. In other words, it was possible to show that as regards efficiency, the modern photovoltaic systems are not inferior to photosynthetic structures.

Examination of the dependence of the magnitude of current and potential of pigmented electrodes on the $\mathrm{pH}$ value of the electrolyte gave an unexpected result. It was observed that at a fixed value of $\mathrm{pH}$ in darkness these values are almost identical with the values in platinum electrodes in the absence of the pigment in them. This indicates that the pigment film was penetrated by a large number of pores (Fig. 2) [27; 34].

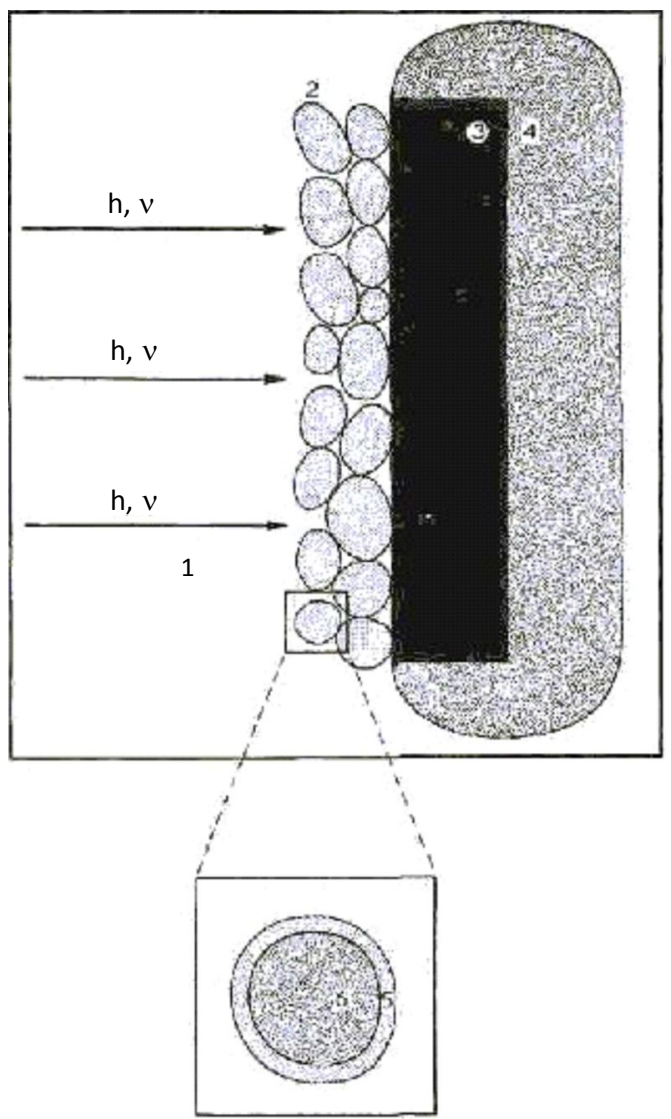

Fig. 2. Scheme of an electrode coated with a layer of pigment:

1 - electrolyte; 2 - pigment layer; 3 - platinum electrode; 4 - insulating layer; 5 - thickness of layer penetrated by incident light; 6 - main body of the pigment suspension

The methods of the preparation of films, the values of current, potentials and the dynamics of these values unambiguously show that they used porous films, but the interpretation of the observed relationships was based on the considerations regarding the monolithic pigmented layer of the electrode. This was followed by the development of methods of production of pore-free films and at the present time it is possible to specify the main types of photovoltaic effects in the films of semiconductor pigments contacting, on the one side, with the electrolyte and, on the other side with the metal $[16 ; 17 ; 27 ; 34 ; 35]$ (Fig. 3).

The nature of the generation of photoresponse in the films differs principally. The values of current and their kinetic parameters differ tens, hundred or more times. The previously described 


\section{ТЕХНИКО-ТЕХНОЛОГИЧЕСКИЕ ИННОВАЦИИ}

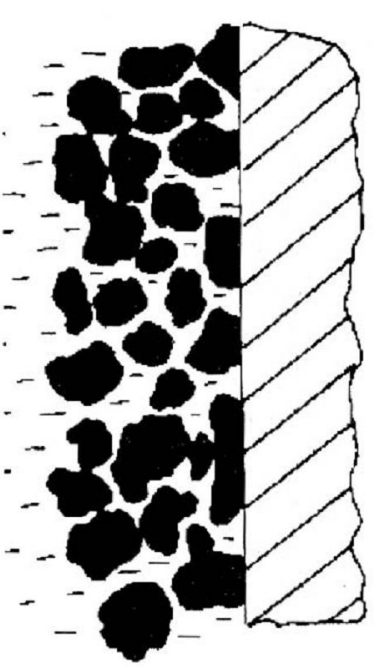

a

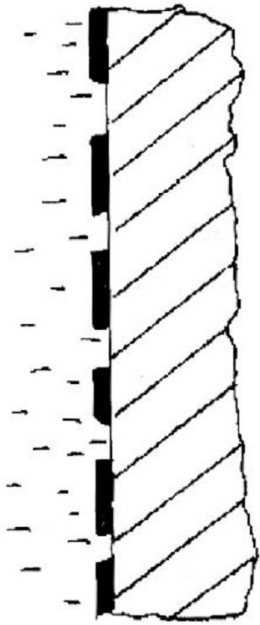

$\mathrm{b}$

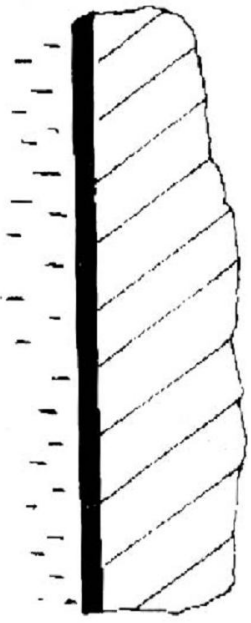

c

Fig. 3. Schematic of three types of pigment films (photovoltaic effects)

Dark areas show the pigment, dashes indicate electrolyte, the metal is shaded by solid inclined lines. $a-\mathrm{a}$ thick porous film (light does not reach the pigment-metal contact).

Light-induced potential aries due to a change in concentration of potential-governing ions at the electrode surface $(\varphi=\mathrm{A}(\mathrm{B}-\mathrm{ln} \mathrm{C}) ; \varphi$ is light-induced potential; $\mathrm{A}=\mathrm{RT} / \mathrm{nF} \mathrm{R}, \mathrm{T}, \mathrm{n}$ and $\mathrm{F}$ have the commonly accepted meaning). The time needed to reach the steady photo-induced potential is of oder minutes, the dark current $\gg 10^{-6} \mathrm{~A} / \mathrm{cm}^{3}$. $b$ - intermediate type.

$c-\mathrm{a}$ thin nonporous film (light penetration depth exceeds the film thickness).

The response to illumination is a result of semiconductor processes in the bulk of the film and its boundaries. The time taken to reach the steady photo-induced potential is a fraction of second, the dark current is $10^{-12} \mathrm{~A} / \mathrm{cm}^{3}$

considerations enabled us to start investigations in the area of structural-functional modelling, the development of artificial systems reproducing the structure (composition) and function of natural photosynthetic formations. The analysis of literature data on the generation of oxygen from water in physical-chemical systems (electrolysis, photolysis and radiolysis of water) and also the data obtained in our laboratory on the generation of oxygen in natural and modelling systems have made it possible to propose an original schema of photosynthetic release of oxygen [27; 34].

According to the schema, the generation of a single molecule of oxygen requires at least four light quanta, each of which generates an 'electron-hole' couple, and the electron is used in the reaction $\mathrm{H}^{+}+\mathrm{e} \rightarrow \mathrm{H}$, required for subsequent fixation of $\mathrm{CO}_{2}$. The surface of lamellae (sheets from which chloroplasts is produced) is a unique photoelectrode, consisting of alternating anodic and cathodic microregions (Fig. 4) $[27 ; 34 ; 35]$. On the whole, the proposed schema of the dissociation of water has made it possible to explain several relationships in the photosynthetic generation of oxygen.
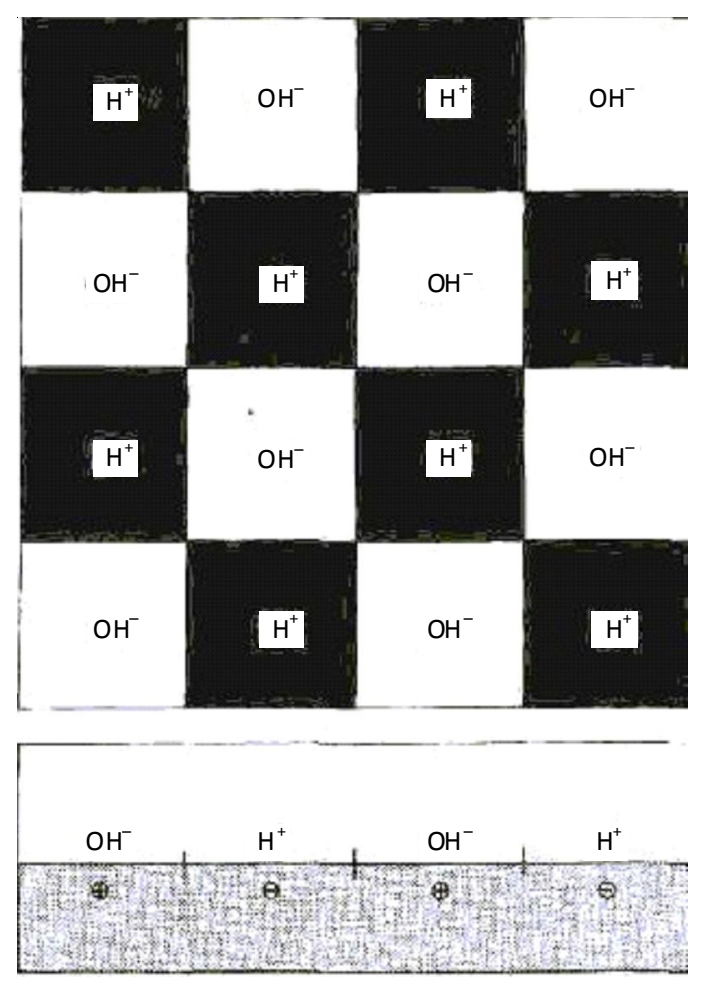

Fig. 4. Structural scheme of the absorbed layer on the surface of the pigment (view from above and from side) 
The experimental confirmation required many years of work resulting in the development of the new concept of photosynthesis.

\section{Hydrogen peroxide - source of photosynthetic oxygen (hydrogen)}

\section{The effect of hydrogen peroxide on the kinetics of generation of oxygen during photosynthesis}

The sequence of dissociation of water during photosynthesis, proposed by us in 1973, may be represented in the form: $\mathrm{H}_{2} \mathrm{O} \rightarrow \mathrm{H}_{2} \mathrm{O}_{2} \rightarrow$ $\rightarrow \mathrm{HO}_{2} \rightarrow \mathrm{O}_{2}$, i.e. water is oxidized to hydrogen peroxide which, in the final analysis, results in the generation of molecular oxygen (see the previous chapter). At present, there is a large number of literature data indicating the participation of hydrogen peroxide as an intermediate product in the course of formation of oxygen. We attempted to use the kinetic methods for confirming the participation of hydrogen peroxide in the course of photosynthetic generation of oxygen. For this purpose, we proposed a kinetic model based on the representation of vector algebra and projection geometry $[27 ; 44]$. The results of kinetic analyses and the experimentally obtained changes of the kinetics of photosynthetic generation of oxygen in the presence of exogenous hydrogen peroxide indicate that it is capable of penetrating in light into the oxygen-generating complex of growth instead of water and act as an independent source of electrons and an independent source of generation of oxygen situated outside the fourstage oxygen cycle.

\section{Hydrogen peroxide - a single source of photosynthetic oxygen}

As already reported, the main method of overcoming the problem of photosynthesis is based on the light stage of photosynthesis (the stage of photodissociation of water). The work of current investigators, concerned with the examination of the photosynthesis mechanism, has been and is still directed to finding approaches capable of explaining the mechanism by which the chlorophyll (the photosynthetic oxygen-generating reactions centre) is capable of storing the energy of several light quanta in order to use this energy for the formation of molecular oxygen. Many original studies have been published in the course of these investigations.

Already in our first study, concerned with the justification of the photoelectrochemical hypothesis of photosynthesis [32], we paid attention to the need to take into account the changes of the properties of water in the chloroplast where it is situated between the lamellae with the distance between them not exceeding $100 \AA$. It is well known that the properties of structured liquid (in particular, and/ or situated at the boundary with the solid phase) greatly differ from the properties in the volume. The viscosity of water in capillaries is an order of magnitude higher than the viscosity of water in the volume, and the heat conductivity of water in the layers increases tens of times, dielectric permittivity decreases from 81 (water in the volume) to 3-4 (in the interlayers with a thickness of 0.5-0.6 nm). Similar examples make it possible to assume that the puzzle of biological oxidation of water with the generation of oxygen is 'hidden not only in the properties of the chloroplast but also of the water itself' [ibid.].

The extensive and long-term examination of the physical-chemical properties of water resulted in an unambiguous conclusion: in the nature there is no pure water, and the water always contains an impurity, i.e. hydrogen peroxide. In a thridistillate, the concentration of hydrogen peroxide is $10^{-9} \mathrm{M}$ [8], and in the water of natural reservoirs (seas, rivers, lakes) it reaches $10^{-6} \mathrm{M}$, in rainwater is $10^{-5} \mathrm{M}[27 ; 48]$. The above makes it possible to supplement the equation of biological oxidation of water (2) by another term, i.e. hydrogen peroxide, which was discovered in 1818 by L.J.Thernard and referred to as 'oxidized water' [45]:

$$
\mathrm{H}_{2} \mathrm{O}_{2}, \mathrm{H}_{2} \mathrm{O} \underset{\text { Chlorophyll }}{\stackrel{\text { Light }}{\longrightarrow}}[\mathrm{H}]+\mathrm{O}_{2} \text {. }
$$

At first sight, it may appear that in this case we are talking about some negligibly small impurity, with no relationship to photosynthesis. However, this is not so. By evaporating the aqueous solution of the peroxide, it is possible to increase the concentration tens of times, because 
its volatility is considerably smaller than in the case of water. The method of concentration of the aqueous solutions of hydrogen peroxide by evaporation of water has been used in the chemical practice for a long time now [45]. Transpiration (evaporation of water by plants) evidently plays the same function in addition to the protection of plants against overheating. For each $\mathrm{kg}$ of water, absorbed by the roots from soil, only $1 \mathrm{~g}(1 / 1000$ part of $)$ is used by the plant for the construction of tissue. Thus, the green leaves may be regarded as a unique concentrator of hydrogen peroxide. It should also be mentioned that the second initial substance in photosynthesis is $\mathrm{CO}_{2}$ whose content in air is only $0.03 \%$ (less than the content of inert gases). Its concentration is higher than the concentration of hydrogen peroxide in the initial water. However, the solubility of hydrogen peroxide in water is 7 (!) orders of magnitude higher than that for $\mathrm{CO}_{2}\left(2 \times 10^{5}\right.$ and $4.5 \times 10^{-2}$ mole $/ 1 \mathrm{~atm}$, respectively). This results in a serious consequence. Regardless of the area of formation of $\mathrm{H}_{2} \mathrm{O}_{2}$ (in air, in air bubbles in soil), its concentration in contacting water will be higher than in $\mathrm{CO}_{2}$. Naturally, in this case it is necessary to take into account the initial concentration of these substances. In addition to exogenous hydrogen peroxide, the photosynthesized cell also contains endogenous hydrogen peroxide. Its source in the cytoplasma is the mitochondrin (in high-intensity photosynthesis, it converges to chloroplasts), peroxisoms, etc. For example, up to $40 \%$ of hydrogen peroxide, generated in peroxisoms, are transferred into cytosol. In other words, the hydrogen peroxide in vivo is completely sufficient for explaining the observed intensity of the generation of molecular oxygen from this hydrogen peroxide [27].

The data, obtained in [39], are most interesting from the viewpoint of examining the role of hydrogen peroxide in the generation of photosynthetic oxygen. The authors carried out mass spectrometric examination of photosynthetic generation of oxygen using hydrogen peroxide, marked with respect to oxygen $\left(\mathrm{H}_{2}{ }^{18} \mathrm{O}_{2}\right)$. The results show that $\mathrm{H}_{2}{ }^{18} \mathrm{O}_{2}$ is the source of the entire amount of generated oxygen. It is wellknown [8] that the hydrogen peroxide in chemical systems rapidly exchanges hydrogen (deuterium) with water. This was already established in 1934. However, when using the oxide marked with respect to oxygen, the situation is completely different. As reported in the monograph [45], 'the oxygen of water, used as a solvent, does not take part in the dissociation or reaction of hydrogen peroxide; no exchange was found between the water and the resultant molecular oxygen or oxidized products'. Consequently, if the photosynthesized systems contain water and hydrogen peroxide, it is evident that the dissociation with the generation of oxygen explained case of the latter compound.

In the photoelectrochemical mechanism of formation of oxygen in vivo from two possible sources (hydrogen peroxide and water), the first mechanism is obviously preferred. In our laboratory, using the method of a spinning disk electrode with a ring (the spinning speed up to $3000 \mathrm{rpm}$ ) we showed the catalase activity of chlorophyll films which were in contact with the aqueous solution of hydrogen peroxide. Under the effect of light, the rate of dissociation of hydrogen peroxide increased 2-3 times in comparison with the darkness values [21].

The results obtained in our laboratory and also the critical analysis of the literature data on the photosynthetic generation of oxygen have made it possible to propose a completely new viewpoint. According to the viewpoint, the source of photosynthetic oxygen (hydrogen) is not water but the exogenous and endogenous hydrogen peroxide [19-22; 27].

Naturally, it is difficult for a conventional photosynthetist to understand our position, because in the current literature the water is regarded as a source of oxygen. It is useful to mention that up to the studies carried out by A.P. Vinogradov [49] and S. Ruben [44], which appeared 70 years ago, the majority of investigators of photosynthesis had assumed that $\mathrm{CO}_{2}$ is the source of oxygen in photosynthesis.

At the Fifth International Biochemical Congress (Moscow, 1961), A.P. Vinogradov and V.M. Kutyurin [48] attempted to evaluate the variants of the methods of dehydration of water during photosynthesis. We believe that A.P. Vinogradov had experimental justification for proposing the hydrogen peroxide as a source of oxygen in photosynthesis. We shall discuss the results. The studies [44; 49] show convincingly 
that $\mathrm{CO}_{2}$ cannot be the source of photosynthetic oxygen as assumed at that time by the majority of researchers. This completed the revolutionary break in the examination of the photosynthesis mechanism. Since during the experiments it was not possible to achieve the equality of the isotope composition of the oxygen generated during photosynthesis and the oxygen in water, it would be necessary to introduce an assumption on the effect of breathing on the investigated process [48]. The situation existing in 1961 in this problem was characterised by R. Wurmser [50] as: 'it is almost evident (bold face by me, G.K.) that the generated oxygen comes from water'. In 1975, H.J. Metzner [40] published a large article: 'The dissociation of water during photosynthesis? Critical review'. Analyzing the literature data and his own results, the author concluded that they reject the hypothesis on the oxidation of water in photosynthesis. The study ended with the words: 'If we take together the data of published isotope experiments as a confirmation against the splitting of $\mathrm{O}-\mathrm{H}$ bonds, we should postulate the rapture of another oxygen-containing bond, i.e. or $\mathrm{C}-\mathrm{O}$ bond or $\mathrm{O}-\mathrm{O}$ bond in the peroxide precursor of oxygen' (bold face by me, G.K.).

We have assumed (and we shall remain on these positions) that the pigment system of the chloroplast is a highly autonomous structure, designed for the generation of protons and molecular oxygen.

The role of thermal energy in photosynthesis and correction of the fundamental photosynthesis equation.

It is generally accepted (see any textbook on photosynthesis) that the thermal energy is a waste production of the photosynthetic process. In the case of a high-intensity process, only $0.5-5 \%$ of light energy is used up for photosynthesis, whereas $\sim 95 \%$ of energy 'degrades into heat'. It is difficult to assume that in billions of years of their existence of the earth, the plants have not adapted themselves to a more efficient utilisation of light energy. In 1973, the author assumed that the thermal energy is not only an important but also essential participant of the photosynthetic process $[24 ; 27 ; 34]$. This viewpoint is presented in the most complete form in the study 'Photosynthesis as a thermal process' [35]. According to this concept, in the regions with the size of the order of the chlorophyll molecule, the local temperature may greatly exceed (by several tens of degrees) the temperature of the surrounding medium. According to our estimates, this temperature reaches $70{ }^{\circ} \mathrm{C}$ as a result of the recombination of charge carriers in the reaction centre in which the adsorption of initial substances has not been completed at the given moment. Increase of the temperature inside the chloroplasts accelerates at the diffusion of both the products of photosynthesis and initial substances. An increase of temperature also facilitates the transport of ions through the membrane. According to calculations, the energy required for the transport of anion from the electrolyte into a lipid membrane, is $250 \mathrm{~kJ} / \mathrm{mole}$. However, the energy of transport of the ion (for example, sodium, potassium) through a membrane channel is considerably lower (approximately $20 \mathrm{~kJ} / \mathrm{mole}$ ) [47].

Already at the start of previous century, K.A. Timiryazev [ibid.] proposed a hypothesis regarding the effect of thermal energy in photosynthesis. He assumed that the heating of chloroplasts, caused by sunlight, may be sufficient for the occurrence, in the chloroplasts, of a process thermodynamically reversed in relation to combustion, and, consequently, this may be used to explain the principle of photosynthesis. This viewpoint is at present of only historic interest because it was criticized. However, in the light of our considerations regarding hydrogen peroxide as a source of molecular oxygen in photosynthesis and local heating of the chloroplasts, it is possible that this hypothesis will be developed further.

It may be assumed that in photosynthesis together with the photoelectrochemical mechanism, there is also the possibility of the thermal dissociation of hydrogen peroxide as the release of molecular oxygen. The thermal stability of water is incomparably higher than that of hydrogen peroxide $[27 ; 45]$.

An additional confirmation of the possibility of thermal dissociation of $\mathrm{H}_{2} \mathrm{O}_{2}$ in photosynthesis may be the data of modelling systems - the films of phthalocyanine (synthetic analogue of chlorophyll) on a Pt electrode which is in contact with the electrolyte, where the dependence of the photopotential of the films of phthalocyanine on heating of the electrolyte may be examined. At a temperature higher than $80^{\circ} \mathrm{C}$, the photoresponse cannot be recorded. This can be naturally explained by the thermal dissociation of hydrogen peroxide formed on the surface of the platinum electrode [26; 27]. 
It should be mentioned that the assumptions regarding the local heating of chloroplast, introduced by us in 1973, were initially met with excessive criticism, but in recent years these concepts in the sphere of biophysics do not lead to any dispute (see, for example, [34]). In addition, a number of studies have been published recently on polymers, the theory of the photographic process, media for optical memory, glasses, where the assumption on the local temperature is used successfully for explaining the observed relationships. In the monograph by S.F.Timashev 'Physics and chemistry of membrane processes' [47], the role of the local heating is treated in a special section.

On the basis of all these considerations it may be assumed that of the local equation of photosynthesis should include not only light but also thermal energy [19-22; 27]. The point is that in the implicit form, the thermal energy, from our viewpoint, has been included in the general equation of photosynthesis for a long time. We shall pay attention to the thermodynamic potential of dissociation of water. The minimum difference of the potentials, required for the electrolysis of water at $25^{\circ} \mathrm{C}, 1 \mathrm{~atm}$, and on the condition of the supply of thermal energy, is $1.23 \mathrm{~V}$. The thermoneutral potential of dissociation of water at $25{ }^{\circ} \mathrm{C}$ is $1.47 \mathrm{~V}$. In all investigations into photosynthesis, only the first magnitude $(1.23 \mathrm{~V})$ has been used, but the necessity for supplying thermal energy in this case is simply not mentioned.

Thus, the previously presented data on the exo- and endogenous hydrogen peroxide as a source of oxygen (hydrogen) in photosynthesis and the role of thermal energy make it possible to write the basic equation of photosynthesis in the following form [19-22; 27]:

$$
\mathrm{CO}_{2} \text { (air) }+\mathrm{H}_{2} \mathrm{O}_{2} \text { (water) } \stackrel{\text { Light energy }}{\longrightarrow} \text { carbohydrates }+\mathrm{O}_{2} \text {. }
$$

The main difference between this equation and equation (1) is the replacement of $\mathrm{H}_{2} \mathrm{O}$ by $\mathrm{H}_{2} \mathrm{O}_{2}$, and the water plays the role of the reaction medium for $\mathrm{CO}_{2}$ and $\mathrm{H}_{2} \mathrm{O}_{2}$. It should be mentioned that the identical situation was recorded previously with the $\mathrm{CO}_{2}$. Initially, it was assumed that 'air' (my italics, the author) damaged by the combustion of candles takes place in photosynthesis, and, subsequently, the modification $-\mathrm{CO}_{2}$ (G. Senebier, 1782) was introduced. The concentration of $\mathrm{CO}_{2}$ in air is only $0.03 \%$. It is also possible that in future new components of both air and natural water, taking part in photosynthesis, will be detected. For example, reports have appeared according to which the inert gases affect the rate of splitting of cells. Therefore, we regard it as useful to write in the main photosynthesis equation air in addition to $\mathrm{CO}_{2}$ and water together with $\mathrm{H}_{2} \mathrm{O}_{2}$ and, naturally, photosynthesis, like any other life processes, is not possible without water.

Two words about thermal energy. The sign $(+/-)$ in equation (8) indicates that at high densities of the light the leaf (chloroplast) transfers the energy to the surrounding medium, and at low densities, it takes the energy from the surrounding medium. In the latter case, the coefficient of transformation of solar energy may be higher than $100 \%$ because the contribution of thermal energy is not taken into account. A similar situation was found in the early stages of examination of the efficiency of operation of fuel elements.

Thus, we shall make a conclusion. A new concept, according to which the source of oxygen (hydrogen) in photosynthesis is the exogenous and endogenous hydrogen peroxide, and not water, has been proposed. The dissociation of hydrogen peroxide with the generation of molecular oxygen is possible either by photoelectrochemical and/or thermochemical mechanism. The thermal energy is not a reject of photosynthesis, and becomes an essential participant of this process. What consequences result from these considerations?

\section{Some consequences resulting from the new concept of photosynthesis}

\section{The effect of hydrogen peroxide on the growth of plants}

Within the framework of the proposed concept it was reasonable to propose that the variation of the concentration of peroxide in water has a significant effect on the rate of growth of plants because photosynthesis in particular determines the rate of the physiological processes. The authors of [2] presented results of experimental verification of this assumption. 
Naturally, the effect of different amounts of exogenous hydrogen peroxide may have an appropriate effect also on the rate of generation of endogenous peroxide. The mechanism of participation of hydrogen peroxide in the physiological processes of growth is being studied intensively at the present time. Peroxide determines the intensity of photophosphorylation, photobreathing, fungitotoxicity of the surface of leaves, etc.

In order to record the growth of plants in the presence of hydrogen peroxide, in addition to the traditional biological approach, we have also used the recently proposed method of laser interference auxanometry [26;27]. It should be mentioned that the problem of the growth of plants is one of the central problems in current phytophysiology.

Analysis of the literature shows that the stimulating effect of hydrogen peroxide on the growth and development of plants has been known for a long period of time. Already at the beginning of this century, it was known that the solutions of hydrogen peroxide stimulates the growth of seeds. The introduction of hydrogen peroxide into soil increases the yield of corn, soya beans, accelerates the growth of seeds, but the reason for this effect, as reported in the above investigations, was not clear [45].

\section{Using plants for the generation of air in a closed volume}

If we compare the traditional form of the main equation of photosynthesis (1) with the equation (8) proposed by us, it may be seen that in addition to the differences mentioned previously, there is one important consequence in our view. The classic equation of photosynthesis assumes that there is complete agreement with respect to the initial and final products between photosynthesis and breathing (equation (1) read from right to left, is the equation of breathing). In the concepts proposed by us, the relationship between the fundamental biological process and breathing is complicated because the final product in breathing is water which, in our view, does not split during photosynthesis. This is illustrated by the diagram of formation of oxygen and its usage during breathing (Fig. 5).

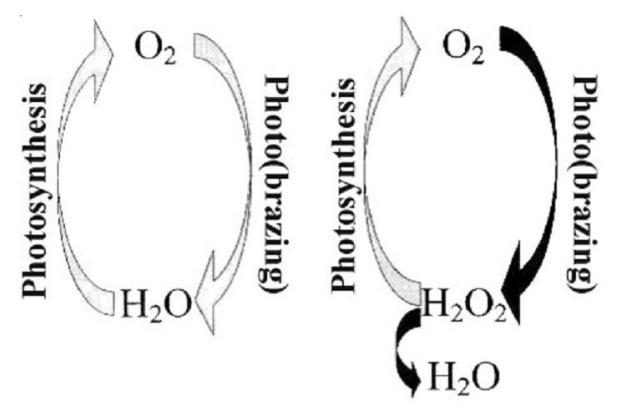

A B

Fig. 5. The relationship between photosynthesis and (photo) breathing within the framework of the conventional considerations regarding photosynthesis $(A)$ and in accordance with the concept proposed by the author of the article $(B)$

It is well-known that in addition to photosynthesis, the leaf is characterized by the occurrence of an opposite process stimulated by light, i.e. the generation of carbon dioxide and absorption of oxygen (photobreathing). In the dark conditions, the intensity of the process, opposite photosynthesis (dark breathing), is 5$7 \%$ of photosynthetic gas exchange (plants, like living creatures, require oxygen). However, the intensity of photobreathing is an order of magnitude higher in comparison with dark breathing and equals $\sim 50 \%$ of photosynthetic gas exchange $[7 ; 11]$. Since the photobreathing greatly reduces the rate of real photosynthesis and, consequently, the productivity of the plants, a larger number of attempts have been made to liquidate this process (or, at least, reduce its intensity). These attempts have not been successful. According to V.I. Chikov [78], "none of the directions in the search for the methods of decreasing the intensity of photobreathing have resulted in a positive result for increasing the productivity of the plants. In addition, it is believed that the conditions, suppressing photobreathing, also decrease the productivity of the plants'.

Previously, it was mentioned that breathing is accompanied by the formation of endogenous hydrogen peroxide. In accordance with the proposed concept of photosynthesis, the endogenous hydrogen peroxide is a source of not only oxygen, injected into the atmosphere, but also of hydrogen used in the synthetic processes of growth. It should be mentioned that photobreathing is the most active when the plant is supplied with 
abundance of mineral nitrogen, i.e. favourable conditions are created for the growth of biomass. The stimulating effect of the exogenous hydrogen peroxide (at the optimum concentration of the latter) was examined in the previous section.

Thus, it may be assumed that the activity of synthetic processes in the plants is determined in approximately equal parts by the intensity of photosynthesis and photobreathing. Naturally, photobreathing uses the products stored as a result of photosynthesis plus atmospheric oxygen. A further examination of this process by physiologists of plants would enable, in our opinion, the development of the optimum technology cultivating of agricultural plants.

The considerations described here cast doubts on the exclusive role of plants in the formation of the current oxygen atmosphere of the earth, widely cited in the biological literature. We believe that in the geochemical investigations which, in our view, are most important in the given problem, it is easy to find an opposite viewpoint.

Explanation of the mechanism of generation of photosynthesing oxygen is very important in the current period because of the development of space technology, the development of essential conditions for the life of man in a closed space. If the plants ensure the supply of oxygen to our atmosphere, it is natural that it should be attempted to use them for the generation of air in a closed system, for example, in a space station. Our concept of photosynthesis is directly related to this problem.

In September of 1991, eight volunteers started two-year tests in the Biosphere-2 complex, isolated from the outer world. The complex is a prototype of future cosmic stations on the planets of the solar system [1]. The Biosphere-2 is a large experimental system generated for the examination of ecological processes taking place on the earth, and also for the development of the conditions of life activity in future cosmic stations which will be constructed mainly on Mars. The experiment was planned for 2 years. However, in June 1992, the oxygen content inside the complex was greatly reduced (from 20.94 to $16.4 \%$ ). The subsequent decrease of the oxygen concentration was $0.25-0.3 \%$ per month and it was therefore necessary to supply oxygen into the complex [39]. A special commission has been formed for investigating the reasons resulted in a decrease of the oxygen concentration.
We believe that one of the reasons resulting in the unsatisfactory dynamics of oxygen in the Biosphere-2 is associated with the fact that the developers of the object used the conventional assumptions according to which the water is a source of oxygen in photosynthesis. In accordance with our concept of photosynthesis (see equation (8) and Fig. 5), for the normal functioning of a hermetically sealed complex, containing plants, it is necessary to ensure the occurrence in the complex of the processes resulting in the generation of hydrogen peroxide. On the Earth, the hydrogen peroxide forms as a result of storm discharges, the radiolysis of undergroung water etc.

\section{Artificial photosynthesis and the problem of life origin}

The attempts to model natural photosynthesis have been made since long ago. Back in the early 20th century, there were studies aimed to reproduce the fundamental biological process or its separate steps by means of simple photochemical systems [27]. Currently, the number of publications dealing with this topic increases in the avalanche-like fashion (Fig. 6). However, the attempts did not result in the design of artificial physicochemical systems able to form organic products from carbon dioxide and water with simultaneous evolution of molecular oxygen under the action of visible light. It was not until 1969 that only one of the key functions of chloroplast was reproduced for the first time, in particular, photocatalytic evolution of molecular oxygen from water under the action of light absorbed by synthetic analogs of chlorophyll [22; 50].

What is the main obstacle that precluded implementation of artificial photosynthesis despite numerous attempts? Probably, the traditional equation of photosynthesis bears some error, which prevents implementation of the process in vitro.

In 1993, a new photosynthesis equation was proposed at the Institute of Chemical Physics of the RAS and substantiated in detail in a monograph [27]. According to this equation, exo- and endogenic hydrogen peroxide rather than water serves as the source of oxygen (hydrogen) in the photosynthesis. In chloroplast, there is one hydrogen peroxide molecule per chlorophyll molecule [ibid.]. As shown by quantum chemical 


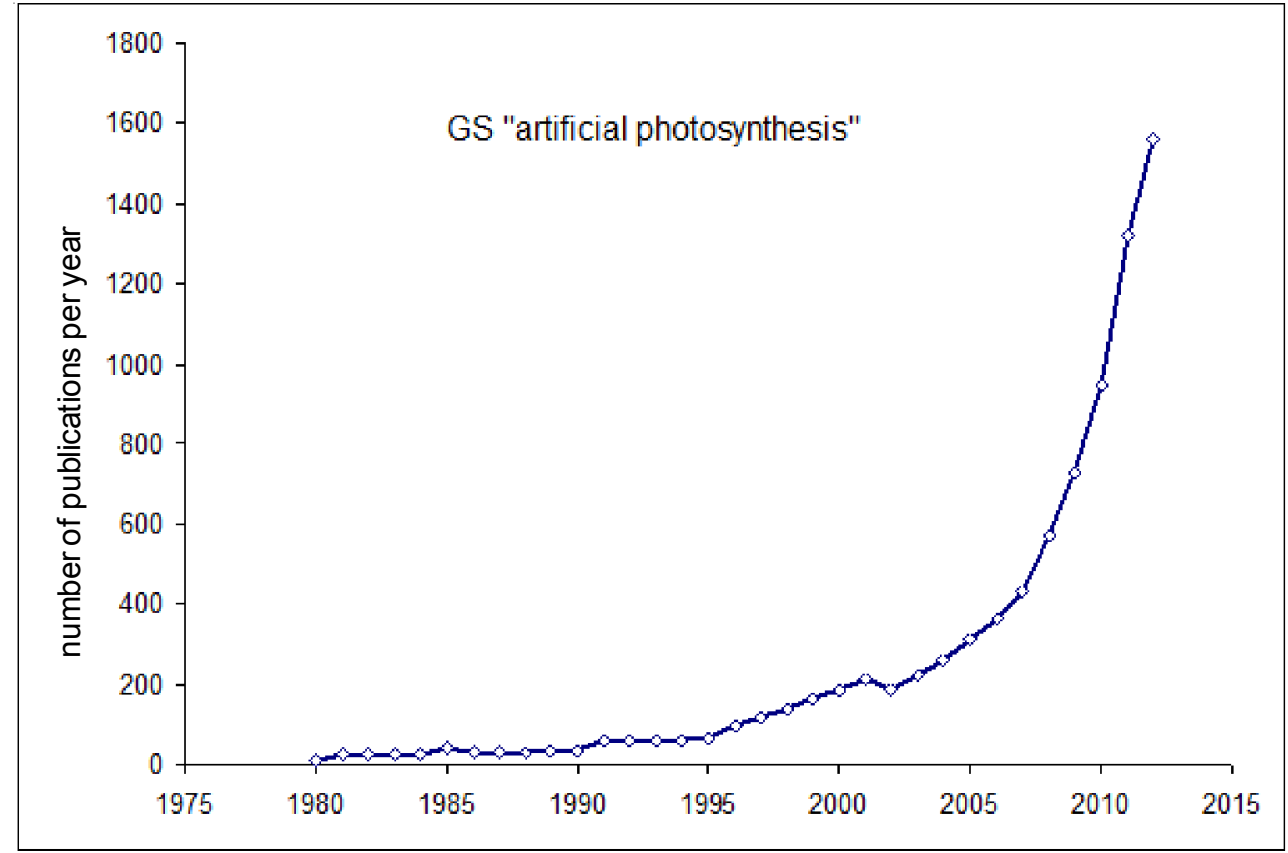

Fig. 6. Annual number of publications mentioning artificial photosynthesis (1980-2012)

calculations, the bond energy of peroxide with chlorophyll dimers is higher than that for water. Depending on the configuration of the dimeric complex, the difference may reach $3.8 \mathrm{kcal} / \mathrm{mol}$.

In 1994 we proposed to organize the international project "Artificial photosynthesis" [17]. It should be noted that the developed concept allows to see a new approach to the problem artificial photosynthesis. Thermodynamic estimates of the enthalpy $\left(\Delta \mathrm{H}^{\circ}\right)$ and the Gibbs energy $\left(\Delta \mathrm{G}^{\circ}\right)$ for reactions of $\mathrm{CO}_{2}$ both with water and with hydrogen peroxide to give formaldehyde, formic acid, glucose, and other products were reported [36]. The results demonstrated unambiguously that syntheses of organic compounds from $\mathrm{CO}_{2}$ and $\mathrm{H}_{2} \mathrm{O}_{2}$ requires less energy than the corresponding reactions using water. Indeed, replacement of $\mathrm{H}_{2} \mathrm{O}$ by $\mathrm{H}_{2} \mathrm{O}_{2}$ decreases the $\mathrm{G}^{\circ}$ of product formation by $30 \%$ for formaldehyde, by $34 \%$ for methanol, and by $42 \%$ for formic acid.

On the basis of the above data, a successful attempt was made in 2004 to detect the formation of organic compounds upon the action of light on an aqueous suspension of adsorbed phthalocyanines, which were used as synthetic analogs of chlorophyll $[35 ; 36]$. The suspension contained $0.2 \mathrm{~mol} / \mathrm{L}$ of hydrogen peroxide and $0.4 \mathrm{~mol} / \mathrm{L}$ of $\mathrm{NaHCO}_{3}$. By means of chemical analysis and spectrophotometry, photocatalytic formation of formaldehyde was detected (Fig. 7).

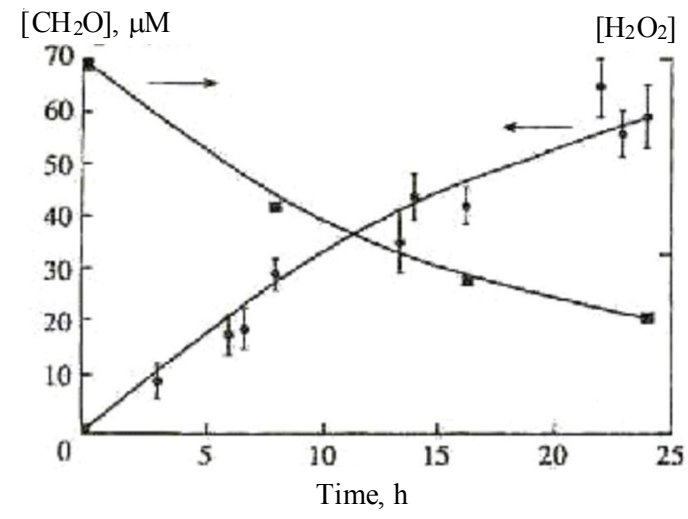

Fig. 7. Kinetics of phormaldehyde accumulation and hydrogen peroxide consumption

in the photocatalitic reduction bicarbonate anion $\left(\left[\mathrm{NaHCO}_{3}\right]_{0}=0.4 \mathrm{M}, 20^{\circ} \mathrm{C}\right.$, photocatalist is aluminium phtalocyanine) (time, hours)

Analysis of the IR spectra of the irradiated reaction mixture attested to possible formation of organic products of various nature in such systems $[35 ; 36 ; 40]$.

In work [28] deals with a GC/MS detection of photogenerated organic products in an aqueous suspension of adsorbed aluminum phthalocyanine, $\mathrm{H}_{2} \mathrm{O}_{2}$, and $\mathrm{HCO}_{3}$ and in the system containing $\mathrm{H}_{2} \mathrm{O}_{2}$ and $\mathrm{CO}_{2}$, which we considered as a new step towards artificial photosynthesis.

The photophysical and photochemical properties of phthalocyanine are similar to those of chlorophyll but the stability against destructive 
impacts is much higher. This is why phthalocyanine was chosen for the experiment [27]. We used spectral grade chlorinated aluminum phthalocyanine (Kodak). Since chlorophyll is linked in vivo to a support (protein), we used phthalocyanine also in the adsorbed state. As a support with developed surface, we took silica gel L 40/100, which allowed easy separation of the pigment from the reaction products by mere centrifugation. Aluminum phthalocyanine was adsorbed from a solution in DMF. The adsorbed amount was measured as the decrease in the pigment concentration in solution by spectrophotometry on a DR/4000V instrument (HACH-Lange, USA). As found from the adsorption isotherm, a monomolecular layer of the phthalocyanine metal complex is formed on the support surface when the phthalocyanine concentration in the initial solution is in the range. 10-4 mol/L [40]. The preliminary experiments showed that the highest photocatalytic activity of the adsorbed aluminum phthalocyanine in decomposition of $\mathrm{H}_{2} \mathrm{O}_{2}$ is observed in the region of pre-monomolecular coverage of the support surface. Considering these data, the catalysts were prepared by adding $10 \mathrm{~mL}$ of a $5.10-4 \mathrm{M}$ solution of aluminum phthalocyanine to $1 \mathrm{~g}$ of silica gel. The adsorbates contained 5.4. 10-7 mol of the pigment per $\mathrm{g}$ of silica gel.

Kinetic experiments were carried out in $10 \mathrm{~mL}$ of a reaction mixture containing $\mathrm{H}_{2} \mathrm{O}_{2}$ $(0.2 \mathrm{~mol} / \mathrm{L})$, special purity grade $\mathrm{NaHCO}_{3}$ $(0.4 \mathrm{~mol} / \mathrm{L})$ (Reakhim), and supported catalyst $(200 \mathrm{mg})$ in distilled water. The suspension was distilled in a visible light with intense stirring. A halogen lamp (150W) fitted with lenses, a condenser, and a KS-13 light filter cutting off the radiation below $630 \mathrm{~nm}$ was used as the source of visible light. The light flux power was $10 \mathrm{~mW} /$ $\mathrm{cm}^{2}$. A quantitative determination of formaldehyde showed that its concentration reaches $10-5 \mathrm{~mol} /$ $\mathrm{L}$ after $24 \mathrm{~h}$ of irradiation. By this moment, more than $70 \%$ of the initial amount of $\mathrm{H}_{2} \mathrm{O}_{2}$ has been consumed, mainly via (photo)catalytic disproportionation. Under these conditions, we did not observe destruction or poisoning of the catalyst. The conclusion about the stability of the metal complex is also confirmed by the results of control runs carried out without $\mathrm{NaHCO}_{3}$ in which no formaldehyde was detected. This implies that only $\mathrm{CO}_{2}\left(\mathrm{HCO}_{3}^{-}\right)$can serve as the source of $\mathrm{CH}_{2} \mathrm{O}$.
Other products were analyzed by the $\mathrm{GC} /$ MS method. The GC/MS facility used to analyze the samples comprised a Thermo Focus GC gas chromatograph and a Thermo DSQ II mass spectrometer with a $60 \mathrm{~m} .0 .25 \mathrm{~mm}$ capillary glass column ( 0.25 .m thick $100 \%$ dimethtylpolysiloxane as the stationary phase). The temperature program of the chromatograph included 10-min heating from 35 to $80{ }^{\circ} \mathrm{C}$ (heating rate $1{ }^{\circ} \mathrm{C} / \mathrm{min}$ ), then to $110^{\circ} \mathrm{C}$ (heating rate $5^{\circ} \mathrm{C} / \mathrm{min}$ ), and to $210{ }^{\circ} \mathrm{C}$ (heating rate $10{ }^{\circ} \mathrm{C} / \mathrm{min}$ ). The injector temperature was $200{ }^{\circ} \mathrm{C}$ and the interface temperature was $250^{\circ} \mathrm{C}$. Electron impact ionization was used, the electron energy being $70 \mathrm{eV}$ and the mass spectrum being scanned in the range of 20-270 amu. Helium served as the carrier gas, the flow rate was $1 \mathrm{~mL} / \mathrm{min}$. Compounds were identified using the NIST library of mass spectra. Under the conditions used, the GC/MS method revealed organic compounds of alcohol and ketone classes in the reaction mixture (Fig. 8). If one of the components (hydrogen peroxide, hydrocarbonate, or phthalocyanine) is removed from the reaction mixture, organic products cannot be detected.

In the next experiment, $\mathrm{NaHCO}_{3}$ was replaced by gaseous $\mathrm{CO}_{2}$, which was passed continuously through the suspension during the irradiation $(24 \mathrm{~h})$. All other conditions were the same as in the previous experiment. The GC/MS analysis of the reaction mixture after irradiation showed the presence of formic acid (Fig. 9).

Note that in this run, too, GC/MS analysis did not detect organic compounds when either hydrogen peroxide or carbon dioxide was missing.

Positive results of experiments using hydrogen peroxide are of considerable interest. They open up attractive prospects: selection of the most appropriate pigment (variation of the ligands and the central atom), support, and reactant ratio, which may provide significant results. At the current stage, we can say with confidence that a new step was made towards artificial photosynthesis in a purely abiogenic system. The value of these results is beyond the framework of photosynthesis. Particular paths to biofuel from carbon dioxide and hydrogen peroxide have been outlined, which is of paramount importance for modern ecology. According to various estimates, the period when the mankind will face the problem of exhaustion of the resources of fossil combustibles is near at hand. 


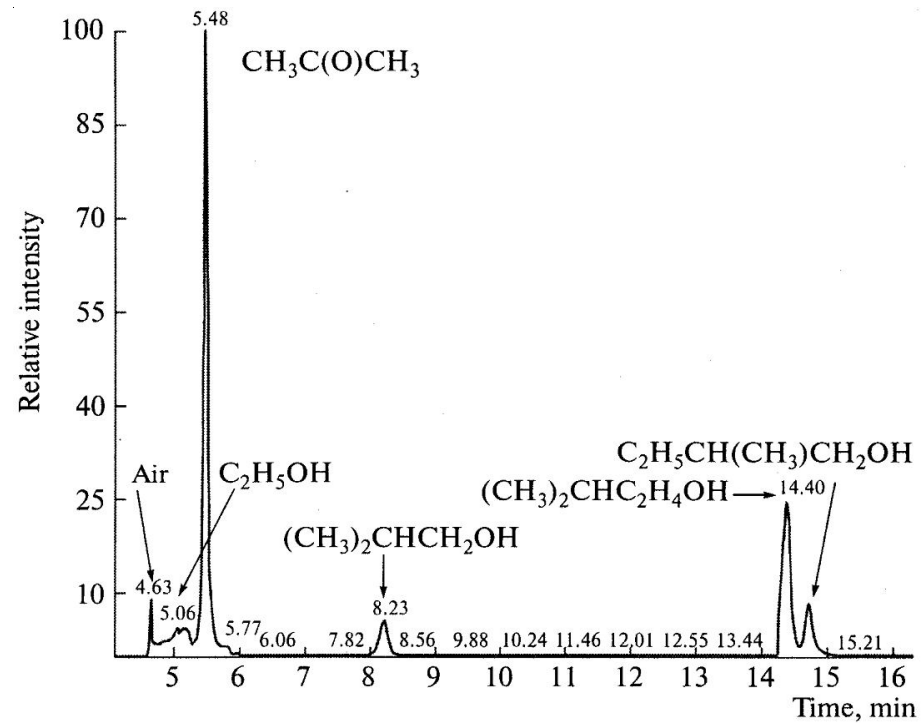

Fig. 8. Composition of the organic products in the reaction mixture containing $\mathrm{H}_{2} \mathrm{O}_{2}, \mathrm{NaHCO}_{3}$, and adsorbed aluminum phthalocvanine after $24 \mathrm{~h}$ of irradiation according to $\mathrm{GC} / \mathrm{MS}$ data

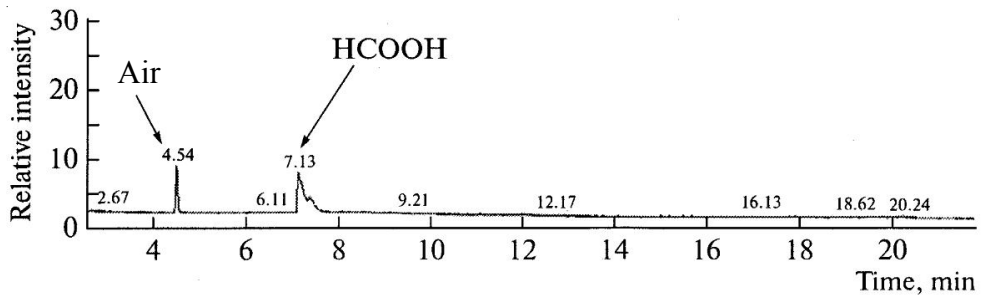

Fig. 9. Formation of formic acid in the reaction mixture containing $\mathrm{H}_{2} \mathrm{O}_{2}$ and adsorbed aluminum phthalocyanine after $24 \mathrm{~h}$ of irradiation with continuous purging with $\mathrm{CO}_{2}$ according to $\mathrm{GC} / \mathrm{MS}$ data

The obtained results can be used also in considering the problem of cosmic origin of life, as hydrogen peroxide was detected in space objects $[5 ; 9 ; 10 ; 12]$.

\section{Conclusion}

In the justification of the new concept of photosynthesis resulting from all our previous investigations, carried out in the laboratory, we use the following results. Photosynthesis (or, more accurately, its light stage - the generation of oxygen) is basically a relatively simple physicalchemical process taking place in a highly complicated biological system. The pigments of the chloroplasts represented a highly autonomous system whose function is mainly the absorption of light (therefore, the intensive colour of the pigments) and transformation of the light to chemical energy. The effect of light in the chloroplasts results in the formation of an excess number of protons ensuring the possibility of occurrence of ferfermentation reactions leading to the synthesis of hydrocarbons. The results of our literature analysis and the data obtained in our laboratory convincingly indicate that the source of oxygen (hydrogen) in photosynthesis is the exogenous and endogenous hydrogen peroxide. The water plays the role given to the solvent in conventional chemical reactions. Naturally, the water protons may take part in the formation of endogenous hydrogen peroxide. However, the problem of dissociation (oxidation) of water is not so important for us at the moment because the amount of hydrogen peroxide ('oxidised water', the initial name of hydrogen peroxide) in the chloroplasts (cytoplasma) is such that it is possible to explain the experimental detected intensity of generation of oxygen (for each molecule of chlorophyll, including the molecule of the antennae, there is one molecule of hydrogen peroxide). Evidently, if the system contains water and hydrogen peroxide, only hydrogen peroxide will undergo photodissociation 
under the effect of visible light. Naturally, the development of detailed schema of the dissociation of hydrogen peroxide in photosynthesis requires a certain period of time. As an example, in current catalysis, hydrogen peroxide is used widely in heavy and light organic synthesis. This is one of the oldest variants of catalysis. However, according to the descriptive expression by Academician I.I. Moiseev, "Hydrogen peroxide is widely used in organic synthesis industry, although the mechanism of its action is not elucidated fully" (Report of the seminar on Catalysis in ICP RAS).

The participation of hydrogen peroxide in the photosynthetic generation oxygen is far more likely than the participation of water, not only from the physical-chemical viewpoint (comparison of the dissociation potentials, thermal stability, etc.). It makes it possible to explain the existence of a large number of physiological processes accompanying photosynthesis. For example, in the case of high-intensity photosynthesis of mitochondria (generators of hydrogen per oxide) and chloroplast 'converge'. In the literature on physiology of plants, transpiration is treated as an 'unavoidable evil', with attempts being made to eliminate it, although these attempts have not been successful. Within the framework of our considerations, transpiration is essential for the concentration of exogenous hydrogen peroxide. The identical situation is also characteristics of the process of photobreathing with which the physiologists 'fight' without success and cannot get rid of it. Our considerations, presented in this article, indicate that the plants accumulate not only light but also thermal energy (unique thermal pump). The significance of the latter is especially large in the plant assotiations where the illumination of leaves because of mutual shading is relatively low (in the individually standing trees, the mutual screening of the leaves is also high). This makes it possible to use a new approach to explaining the fact that the intensity of photosynthesis in the case of slight illumination is almost an order of magnitude higher in comparison with high-intensity illumination.

In conclusion, it should be mentioned that the long-term investigations into modeling and examination of the photosynthesis mechanism, described in the article, have been used by us in the formulation and computer analysis of the model in which the process of search for the solution of a scientific problem by the investigator is examined in the generalised form [21].

\section{Acknowledgements}

I am very grateful to the colleagues and graduates of the Laboratory of Photobionics of the Institute of Chemical Physics. I am also grateful to a large number of undergraduates and graduates (in most cases, of the Physical Department of the Moscow State University and Moscow PhysicoTechnical Institute) for solving the given problems.

I am especially grateful to Academician A.L. Buchachenko, the Head of the Department of the Dynamics of Chemical and Biological Processes of the Institute of Chemical Physics of the Russian Academy of Sciences, for supporting investigations carried out in our laboratory. The experiments in recent years have been supported by continuing financial support of the Russian Fund of Fundamental investigations to which we are grateful (Grants No. 94-02-04972a, No. 95-03-08982a, No. 960334064a, No. 98-0332061a, No. 04-03-32890a and No. 00-15-97404a, 08-03-00875a; the Presidential program "Leading Scientific Schools" (NSh - 2003-2013) - Coordinator Academician A.L. Buchachenko.

2005-2007 Basic Research Program of the Presidium of RAS "Organic and hybrid nanostructured materials for photonics" Program Coordinator Academician M.V. Alfimov.

2005-2006 Program of Presidium of RAS \# 7P-05 "Hydrogen Energy" - Program Coordinator Academician I.I. Moiseev.

2006-2014 Program of the Presidium of RAS № 18 "The problem of origin of the Earth’s biosphere and its evolution" - Program Coordinator Academician E.M. Galimov.

2009-2011 Program of the Presidium of RAS "Chemical aspects of energy" - Program coordinator of Academician I.I. Moiseev.

2004-2007 ISTS project \# 2876 "Research and Development of Photoelectrochemical Light Energy Converters Based on Organic Semiconductors Using the Principles of Photobionics".

2009-2013 ISTS project \# 3910 "Modeling of primary stages of photosynthesis on the basis of nano-sized supramolecular systems". 


\section{REFERENCES}

1. Allen J., Nelson M. Space Biospheres. Arizona, Synergetic Press, 1989. 108 p.

2. Apasheva L.M., Komissarov G.G A New Concept of Photosynthesis: Opening Perspectives. Biology Bulletin, 1996, no. 23, pp. 518-519.

3. Becquerel E., Acad C.R. Generation of Photocurrent Using Rhodamine B Dye and Visible Light. Sci. Paris, 2007, no. 9, p. 561.

4. Becquerel E., Acad C.R. Systemes de Coordonnees Relationnels. Sci. Paris, 1874, no. 79, p. 185.

5. Bergman P., Parise B., Liseau R., at al. Detection of the Hydroperoxyl Radical $\mathrm{HO}_{2}$ Toward $\rho$ Ophiuchi A. $A \& A, 2011$, vol. 531, no. 8, pp. 1-4.

6. Chibisov K.V. Comments on History of Photography. Moscow, Iskusstvo Publ., 1987. 218 p. (in Russian).

7. Chikov V.I. Concept of Photosynthesis: Opening Perspectives. Sorovskii Obrazov. Khimii, 1996, no.11, pp. 2-6. (in Russian).

8. Das T.N., et al. Synthesis of Heterocyclic and Non-Heterocyclic Entities. Indian Chem. Soc., 1982, vol. 59, pp. 85-87.

9. Du F., Parise B., Bergman P. Production of Interstellar Hydrogen Peroxide $\left(\mathrm{H}_{2} \mathrm{O}_{2}\right)$ on the Surface of Dust Grains. $A \& A, 2012$, vol. 544, pp. 1-2. DOI: 10.1051/00046361/201118013.

10. Encreannaz T., Greathouse T.K., Lefevre F., Atreya S.K. Hydrogen Peroxide on Mars: Observations, Interpretation and Future Plans Encrenaz. Planetary Space Sci., 2012, vol. 68, pp. 3-17.

11. Golovko T.K. Breathing of Plants (Physiological Aspects). Saint Petersburg, Nauka Publ., 1999. 190 p. (in Russian).

12. Houtkooper J.M., Schulze-Makuch D. Possibilities for the Detection of Hydrogen PeroxideWater Based Life on Mars by the Phoenix Lander. Planet. Space Sci., 2009, vol. 57, pp. 449-453.

13. Ilatovsky V.A., Komissarov G.G. Especially the Generation of Photocurrent in Pigmented Films During Pulsed Light. Doklady RAN, 2008, vol. 420, pp. 66-69.

14. Ilatovsky V.A., Apresyan E.S., Komissarov G.G. Photoactivity Thin Films of Phthalocyanine Metal Intermediates. Russ. J. Phys. Chem., 1989, vol. 63, pp. 2242-2244.

15. Ilatovsky V.A., Dmitriev I.B., Komissarov G.G. Energy Characteristics of the Photovoltaic Element Based on Zinc Phthalocyanine. Russ. J. Phys. Chem., 1978, vol. 52, pp. 66-68.

16. Komissarov G.G. A New Concept of Photosynthesis Mechanism. Moscow, Editorial URSS Publ., 2006. 234 p.
17. Komissarov G.G. Artificial Photosynthesis: When? Tenth Intern. Conf. Photochem. Conversion and Storage Solar Energy (IPS - 10) Book of Abstracts, 1994, pp. 67-98.

18. Komissarov G.G. Possibility of Photoelectrical Splitting of Water Mechanism in Photosynthesis. Abstracts of the $2^{\text {nd }}$ International Biophysics Congress, Vienna, Austria, 1966, p. 234.

19. Komissarov G.G. A New Concept of Photosynthesis Mechanism. Molecular Constants and Thermodynamic Functions for Some of M3X3 Trimers. Russ. J. Phys. Chem., 1973, vol. 47, pp. 927-932.

20. Komissarov G.G. Possibility of Photoelectrical Splitting of Mechanism in Photosynthesis. UPACAbstr. 5-th Intern. Symp. Macromoleculare Complexes, Bremen, Germany, 1993, p. 420.

21. Komissarov G.G., Avakyanz G.S., Mazo M.A. "Known and unknown" Model Border Crossing and Computer Analysis. Pros. Int. Conf. Nonlinear Word, 2000, p. 110.

22. Komissarov G.G. About the Possibility of Photoelectrochemical Mechanism Once the Position of the Water During Photosynthesis. Biophysics, 1967, vol. 12 , no. 3 , pp. 558-561.

23. Komissarov G.G. Radiative Physics - Yes CO2 Does Create Warming. Chem. Phys. Rep., 1995, vol. 14(11), pp. 1723-1732.

24. Komissarov G.G. Chemistry and Physics of Photosynthesis. Moscow, Znanie Publ., 1980. (in Russian).

25. Komissarov G.G. Current Research in Photosynthesis. Kluwer Academic Publishers, 1990, vol. IV, pp. 107-110.

26. Komissarov G.G. Fotosintez: fizikokhimicheskiy podkhod [Photosynthesis: Physicochemical Approach]. Moscow, Editorial URSS, 2003. 223 p.

27. Komissarov G.G. Fotosintesis: Um Enfoque Fisicoquimico. Editorial URSS, 2005. 258 p.

28. Komissarov G.G. Asymmetric Catalysis: Science and Opportunities. J. Advanc. Chem. Phys., 2003, vol. 2 (1), pp. 28-61.

29. Komissarov G.G., Lobanov A.V., Nevrova O.V., at al. Temperature Dependence of ESR Spectra of Nitroxide Spin Probe in Glassy Polymers. Doklady "Physical Chemistry", 2013, vol. 453, part 2, pp. 275-278.

30. Komissarov G.G. How I Helped A.N. Terenina in the Understanding of the Mechanism of Photosynthesis. Optics and Spectroscopy, 1997, vol. 83,pp. 607-610.

31. Komissarov G.G. Photovoltaic BatteryFunctional Model of Chloroplast. Science in Russia, 1994, no. 5, pp. 52-55.

32. Komissarov G.G., Shumov Yu.S., Borisevich Yu.E. Photovoltaic Battery-Functional Model. Doklady AN SSSR, 1969, vol. 187, pp. 670-673. 
33. Komissarov G.G., Shumov Yu.S. Photosynthesis: Physical-Chemical Approach. Doklady AN SSSR, 1968, vol. 182, pp. 1226-1229.

34. Komissarov G.G. The Inherent and Seemingly Mutually Exclusive Qualities of the Genome of Higher Biosystems Conservatism and Mobility. Sov. Sci. Rev., 1971, pp. 285-290.

35. Komissarov G.G. Photochemical Conversion and Storage of Solar Energy. UPAC Abstracts of the $16^{\text {th }}$ International Symposium on Photochemistry, Helsinky, Finland, 1996, p. 332.

36. Lobanov A.V., Kholuiskaya S.N., Komissarov G.G. Photocatalytic Synthesis of Formaldehyde from $\mathrm{CO}_{2}$ and $\mathrm{H}_{2} \mathrm{O}_{2}$. Dokl. Phys. Chem., 2004, vol. 399, no. 1, pp. 266-268.

37. Lobanov A.V., Vasiliev S.M., Komissarov G.G. Interaction of Hemin and Hydrogen Peroxide: Effect of Media. Macroheterocycles, 2009, vol. 2, no. 34, pp. 268-270.

38. Mano J., Takahashi M.A., Asada K. Oxygen Evolution From Hydrogen Peroxide in Photosystem II: Flash-Induced Catalatic Activity of Water-Oxidizing Photosystem II Membranes. Biochemistry, 1987, vol. 26, pp. 24995-24997.

39. Metzner H., Progress in Photosynthesis Research. J. Theoret. Biol., 1975, vol. 51, pp. 201-216.

40. Nelson M., et al. The Value of the Biosphere2" to Study Ecosystem Processes. Vestnik RAN, 1993, vol. 63, pp. 1024-1036. (in Russian).

41. Nevrova O.V., Lobanov A.V., Komissarov G.G. Tetrapyrrolic Macrocycles With Magnesium, Aluminum and Zinc in Hydrogen Peroxide
Decomposition. J. Charact. Develop. Novel Mater., 2011, vol. 3, no. 3, pp. 172-176.

42. Problems of Ecological Security in Agriculture. Moscow, Sergiev Posad Publ., 2003, p. 25.

43. Ptitsyn G.A., Komissarov G.G. Photocatalytic Processes With Participation of Hydrogen Peroxide in Natural and Artificial Photosynthetic Systems. Sov. Jnl. Chem. Phys, 1994, pp. 2137-2147.

44. Rabinovich E. Photosynthesis. Moscow, Inostr. Lit. Publ., 1959.659 p. (in Russian).

45. Ruben S., Randell M., Kamen M., Hyde J.L. Heavy Oxygen (180) as a Tracer in the Study of Photosynthesis. J. Amer. Chem. Sos., 1974, vol. 63, no. 3, pp. 877-879.

46. Schumb W.C., Satterfield C.N., Wentworth R.L. Hydrogen Peroxide. New York, Reinold Publishing Corporation, 1955. $578 \mathrm{p}$.

47. Stamm E.V., Purmal A.P., Skurlatov Yu.I. Role of Hydrogen Peroxide in Natural Aquatic Environment. Uspekhi Khimii, 1991, vol. 60, pp. 2373-2398.

48. Timashev S.V. Physico-Chemistry of Membrane Processes. Moscow, Khimiya Publ., 1988. 237 p. (in Russian).

49. Vinogradov A.P., Kutyurin V.M. Geochemistry of Rare and Dispersed Elements in Soils. 5-th Int. Biochem. Congr. Moscow, Nauka Publ., 1962, pp. 264-274.

50. Vinogradov A.P., Teis R.V. A Lie-Backlund Approach to Equivalence and Flatness of Nonlinear Systems. Doklady AN SSSR, 1941, vol. 33, pp. 497-499.

51. Wang J.H. Phosphorylation of the Retinoblastoma Gene Product Is Modulated During the Cell Cycle and Cellular Differentiation. Proc. Nat. Acad. Sci. USA, 1969, vol. 62, pp. 653-660.

\section{НОВАЯ КОНЦЕПЦИЯ ФОТОСИНТЕЗА}

\section{Комиссаров Геннадий Германович}

Доктор химических наук, профессор,

Институт химической физики им. Н. Н. Семенова РАН

komiss@chph.ras.ru, gkomiss@yandex.ru

ул. Косыгина, 4, 119991 г. Москва, Российская Федерация

Аннотация. Суть новой концепции фотосинтеза в следующем: источник фотосинтетического кислорода (водорода) - не вода, а экзо- и эндогенная перекись водорода; тепловая энергия является необходимым участником процесса фотосинтеза. Представленная работа по искусственному фотосинтезу выполнена в лаборатории Photobionics в ИХФ РАН.

Ключевые слова: фотосинтез, искусственный фотосинтез, фотогальванический эффект, фотоэлементов, квантовый выход на фототока, хлоропластов, транспирации. 